\title{
O Brincar na Hospitalização de Crianças com Paralisia Cerebral ${ }^{1}$
}

\author{
Bianca Lopes de Souza ${ }^{2}$ \\ Rosa Maria de Araújo Mitre \\ Instituto Fernandes Figueira/Fiocruz
}

\begin{abstract}
RESUMO - O processo de interação social da criança com paralisia cerebral (PC) se configura como um desafio, especialmente durante a hospitalização, quando as habilidades motoras, cognitivas, afetivas e emocionais encontram-se ainda mais comprometidas. A partir disso, este estudo dedicou-se a investigar o papel do brincar, enquanto linguagem própria da infância, no processo de hospitalização de crianças com PC. Foi feita uma pesquisa de abordagem qualitativa, utilizando a observação participante do brincar livre de crianças com PC internadas numa enfermaria pediátrica e entrevistas com os acompanhantes. A partir da análise de conteúdo, foi concluído que o brincar na hospitalização tem papel fundamental no reconhecimento da autonomia, na re-significação do conceito da PC, no ganho de visibilidade e na inclusão dessas crianças.
\end{abstract}

Palavras-chave: criança; paralisia cerebral; desenvolvimento infantil; brincar; hospitalização.

\section{Playing in Hospitalization of Children with Cerebral Palsy}

\begin{abstract}
The social interaction process of children with cerebral palsy poses as a true challenge, especially during hospitalization, when motor, cognitive, affective and emotional abilities are even more debilitated. From this point of view, the present study investigated the role of playing, as childhood's language, in hospitalization of children with CP. The research adopted a qualitative methodology using participant observation during free playing of nine hospitalized children with CP, and interviews with the supporting companions. Based on the content analysis, it was concluded that playing in hospitalization has a fundamental role in the recognition of autonomy, the ressignification of the CP concept, the increase of visibility, and the inclusion of those children.
\end{abstract}

Keywords: child, cerebral palsy; child development; play; hospitalization.

A paralisia cerebral (PC) é um termo que abarca uma série complexa de diferentes distúrbios sensório-motores (Geralis,2007) consequentes de uma lesão estática ocorrida no período pré, peri ou pós-natal. Afeta o sistema nervoso central em fase de formação, maturação e/ou evolução estrutural e funcional. É um tipo de disfunção que envolve distúrbios no tônus muscular, postura e movimentação voluntária.

O grau de comprometimento motor varia de acordo com a dimensão e a localização da lesão. Comumente é classificada a partir do tipo de movimento predominantemente afetado, podendo ser: (1) Monoplegia - um membro afetado; (2) Diplegia - principalmente membros inferiores comprometidos; (3) Hemiplegia - um dos lados afetado; (4) Tetraplegia - afeta os membros superiores e inferiores, principalmente pés e pernas; (5) Hemiplegia Dupla - afeta todo o corpo, principalmente os braços.

Muitas das crianças com PC, por conta dessa condição de base, passam parte de suas vidas dentro do espaço hospitalar. Tanto pela quantidade de intervenções terapêuticas que demandam, quanto pelos frequentes agravamentos do seu quadro clínico, que exigem longos períodos de internação

1 Este trabalho é decorrente de pesquisa realizada no período de 2005/2006, em projeto de bolsa de Iniciação Científica, intitulado "O Papel do Brincar na Interação de Crianças com Encefalopatia Crônica da Infância Hospitalizadas".

2 Endereço para correspondência: Av. Rui Barbosa 716, $5^{\circ}$ andar - Saúde e Brincar, Flamengo. Rio de Janeiro, RJ. CEP 22.250. E-mail: biancalope@iff.fiocruz.br. hospitalar. Sendo assim, o processo de desenvolvimento infantil é atravessado por questões referentes aos déficits e estigmas provenientes da própria condição de $\mathrm{PC}$, além das dificuldades decorrentes do adoecimento e hospitalização.

\section{Correlações entre Paralisia Cerebral e Deficiência}

Segundo Diniz (1996), crianças com paralisia cerebral grave são fenômenos recentes. A manutenção da vida dessas pessoas está ligada aos avanços tecnológicos da medicina, especialmente da neonatologia. No entanto, a equipe de saúde encontra dificuldades em trabalhar com essas crianças. Fixadas numa visão de saúde tecnocrática, nos casos nos quais a cura não é possível, essa equipe possui dificuldades em vislumbrar possibilidades de intervenção. Dessa forma, ao mesmo tempo em que a sobrevivência dessas crianças significa uma vitória, também representa um grande desafio, na medida em que não assegura nenhuma qualidade de vida ou autonomia para elas. Nem tampouco garante uma mudança de paradigma, no qual a pessoa com deficiência possa ser percebida a partir de suas potencialidades e não de suas diferenças.

Nesse sentido, a deficiência precisa ser entendida como um conceito complexo que articula as consequências corporais provenientes de uma lesão à inacessibilidade aos recursos sociais e culturais de um determinado povo. Refere-se a uma estrutura social opressora. Para Diniz (2007), a deficiência caracteriza-se pelo "relacionamento complexo entre as 
condições de saúde de um indivíduo e os fatores pessoais e externos. Denota os aspectos negativos da interação entre o indivíduo e os fatores contextuais" (p.49).

Sendo assim, a maneira pela qual a família se organiza a partir da constatação das deficiências que essas crianças apresentam, envolve a complexidade do processo de aceitação e vinculação desse novo membro à cultura familiar de origem. Nunes, Glat, Ferreira e Mendes (1998) argumentam que a presença de uma criança com deficiência "implica, invariavelmente, para sua família, além da decepção inicial, uma série de situações críticas, geralmente acompanhadas de sentimentos e emoções difíceis de serem enfrentados" (p.16).

Para Glat e Duque (2003), o nascimento de uma criança deficiente desorganiza a família de tal forma que se faz necessário uma flexibilização dos papéis, para impedir que os laços familiares se rompam definitivamente e, assim, possibilitar a aceitação do novo membro. No entanto, essas autoras ressaltam que, em geral, essa "anormalidade" é percebida como uma "imperfeição". Isso, de certa forma, faz com que a família se sinta profundamente culpada. A culpa dificulta a vinculação, aumenta as possibilidades de rejeição e de atitudes super-protetoras, e diminui o investimento na criança, fatores esses que influenciam negativamente a qualidade das expectativas que se criam sobre essas crianças.

Para Cunha (2003), a qualidade das expectativas sobre uma criança influencia o seu desenvolvimento na medida em que altera drasticamente a natureza do seu contato interpessoal. Com base no fenômeno da profecia auto-realizadora (Rosenthal \& Jacobson, 1968), a criança passa a se comportar de acordo com essas expectativas, iniciando-se, assim, um novo padrão de interação. Dessa forma, a criança que apresenta dificuldades provenientes da sua condição está inserida em um meio que, não acreditando na sua potencialidade, investe menos do que seria necessário para valorizar e facilitar a construção de suas habilidades. O não investimento reforça as dificuldades.

Sendo assim, o custo individual e social provocado pela paralisia cerebral grave é imenso. Os graves déficits motores apresentados influenciam o comportamento emocional e social da criança, resultando num desenvolvimento global atrasado. Para Nunes (2003), esses déficits motores atuam negativamente no processo de aquisição da comunicação oral e dificultam o processo de construção de formas alternativas de comunicação. Isso contribui para o isolamento social, a baixa frequência de interações sociais e a ênfase nas funções comunicativas instrumentais ou imperativas. Do ponto de vista terapêutico, a paralisia cerebral grave imprime uma rotina de tratamento complexa, com frequentes intervenções ambulatoriais e recorrentes internações hospitalares. Essa relação intensa entre criança, família e hospital também dificulta a inclusão dessas crianças em outros importantes espaços de sociabilidade comuns na infância, como o próprio ambiente doméstico e o escolar.

\section{O Brincar como Instrumento Terapêutico}

Apesar de o hospital ser um espaço de tratamento para diferentes patologias e quadros clínicos, não está preparado para promover uma atenção integral à saúde da criança.
Comumente, nem os espaços, nem as rotinas hospitalares oferecem o acolhimento e os estímulos necessários para que possam ser minimizados os danos causados pelo adoecimento e hospitalização (Mitre, 2000). Os estímulos adequados ao desenvolvimento infantil dão lugar a estímulos desconhecidos, estranhos e desprazerosos, tais como ruídos de aparelhos, falas incompreensíveis, alteração na rotina diária, além de processos corporais dolorosos e desagradáveis.

Nesse contexto, Saggese e Maciel (1996) apontam a importância do brincar como um instrumento terapêutico. Esses autores apresentam o potencial de promoção de saúde do brincar e propõem a oferta de atividades lúdicas, por equipes interdisciplinares, nas enfermarias pediátricas. Nessa perspectiva o brincar é percebido como um importante recurso para reduzir os danos causados pelo adoecimento e hospitalização da criança.

Segundo Winnicott (1971/1975), o brincar é saúde. Um espaço no qual se dão todas as vivências criativas da criança. O brincar potencializa a interação do indivíduo consigo mesmo e com outros, viabiliza a elaboração psíquica da realidade e favorece o processo de desenvolvimento e a criação de vínculos de confiança pela criança. Já para Maturana e Verden-Zöller (1928/2004), o brincar é um encontro corporal de mútua aceitação. Por meio dele, a criança experimenta uma práxis corporal satisfatória, podendo desenvolver uma adequada consciência corporal e sensorial. O brincar facilita a consciência espacial, a consciência de si e a consciência social. Além de promover o desenvolvimento de forma integral, potencializa o ser e fazer próprio da criança.

Para Santa Roza (1999), o brincar é a linguagem comum na infância. Sob essa perspectiva, a oferta do brincar durante o processo de hospitalização, como prática sistemática dentro das enfermarias, favorece o processo de elaboração psíquica da criança. Também evita o surgimento de patologias e ou outros sintomas ligadas a vivências traumáticas (Santa Roza, 1997).

Nesse sentido, para Takatori (2003), a observação do brincar livre diminui os riscos de intervenções sem sentido e ineficazes. No brincar, a criança se revela a partir de suas potencialidades, apontando possibilidades de inserção social, desenvolvimento e aprendizagem.

Com base nessas considerações sobre o brincar, o presente estudo objetivou a investigação do papel do brincar durante a hospitalização de crianças com paralisia cerebral. Esse questionamento surgiu a partir das constantes negativas de acompanhantes e da equipe de saúde, relacionadas ao convite para a participação das crianças com paralisia cerebral grave em atividades lúdicas nas enfermarias, como se não houvesse a possibilidade delas brincarem ou mesmo interagirem com outras pessoas.

\section{Método}

Esse estudo teve caráter qualitativo. As técnicas utilizadas foram a observação participante e as entrevistas semiestruturadas.

A escolha pela observação participante deveu-se a possibilidade dessa técnica permitir a coleta, de forma criativa, de dados referentes à dinâmica do grupo observado, tais como 
fragmentos de discurso, gestos, interlocuções informais e relações diversas entre os agentes que compõem o cotidiano desse grupo. Já a escolha pelas entrevistas semi-estruturadas relacionou-se à capacidade desse recurso de fornecer dados secundários e primários, inclusive de crenças, comportamentos e atitudes, incluindo em seu perfil uma interação entre pesquisador e entrevistado (Minayo, 1996).

\section{Participantes}

Participaram desse estudo nove crianças com paralisia cerebral grave, com faixa etária variando de 3 a 9 anos, que apresentavam possibilidade de interação social, internadas nas enfermarias pediátricas do Instituto Fernandes Figueira (IFF) / Fiocruz. Para definir interação social, foram utilizados os critérios de avaliação comunicativa desenvolvidos por Hage (1996), ou seja, a criança deveria apresentar alguma forma de intencionalidade, funcionalidade, participação em atividade dialógica e meios de comunicação capazes de viabilizar o processo de interação.

Dentre as crianças, quatro eram do sexo feminino e cinco do sexo masculino. Todas tinham histórico de outras internações, com exceção de uma, que apresentava os primeiros sinais da lesão cerebral na internação ocorrida durante a presente pesquisa. Todas apresentavam tetraplegia, comprometimento motor grave, com dificuldades de locomoção, deglutição, fala e controle esfincteriano. Duas apresentavam também dificuldades de visão e audição. Essa pesquisa foi submetida e aprovada pela Comissão de Ética em Pesquisa do IFF.

\section{Instrumentos e procedimentos}

A observação participante ocorreu durante o período de junho de 2004 a março de 2006, durante os atendimentos de um programa que utiliza o lúdico como intervenção. Durante a pesquisa, os atendimentos aconteciam duas tardes por semana, durante duas horas, com a criação de um espaço lúdico dentro das enfermarias de pediatria e de doenças infecciosas pediátricas (DIPe). As crianças internadas e seus acompanhantes eram convidados a brincar coletivamente nesses espaços, assistidos pela equipe do programa. As crianças que, por alguma questão, não pudessem ir até o setting adaptado, brincavam no próprio leito. Esses atendimentos eram momentos muito ricos para a observação do brincar e do que ele proporciona à criança, aos seus acompanhantes e à equipe de saúde de maneira geral. Após cada observação foi feito registro num diário de campo.

As entrevistas semi-estruturadas foram realizadas com os acompanhantes das crianças. Foram elaboradas a fim de contextualizá-las nas atividades cotidianas, e possibilitar ao responsável a expressão de suas impressões sobre essas crianças no contexto hospitalar. O roteiro das entrevistas foi composto por questões que abarcavam a frequência de internações hospitalares, o contato com outras crianças, as limitações provenientes da $\mathrm{PC}$ e a percepção do acompanhante sobre o brincar no hospital. As entrevistas foram realizadas individualmente durante o período de janeiro a julho de 2005 e tiveram em média 1h30min de duração, tendo sido gravadas e posteriormente transcritas.

Quatro acompanhantes foram entrevistados - os que se dispuseram a participar do estudo, sendo um homem e três mulheres. Duas mulheres eram mães da criança internada e uma era a avó; o homem era o bisavô. Todos eram moradores de periferias do município do Rio de Janeiro, tinham escolaridade até o Ensino Fundamental, e eram as pessoas responsáveis pelos cuidados da criança também em casa.

\section{Análise de dados}

A análise dos dados seguiu a metodologia de análise de conteúdo proposta por Bardin (1971). A análise do conteúdo das entrevistas e das observações registradas no diário de campo foi feita a partir de uma leitura transversal do material, seguida da seleção das categorias mais frequentes tanto nas entrevistas quanto no diário de campo. A partir das categorias foi feita uma articulação com o referencial teórico utilizado. Essa metodologia permitiu o acesso aos significados do brincar no processo de adoecimento e hospitalização dessas crianças e suas famílias.

\section{Resultados}

A análise dos dados nos permitiu perceber que o brincar sistematizado nas enfermarias, adquire diferentes funções junto à criança com PC, tais como: (1) Facilitar a expressão de desejos e necessidades; (2) Auxiliar o processo de elaboração de situações desprazerosas; (3) Facilitar o resgate de atividades do cotidiano da família; (4) Favorecer o processo de construção de vínculo entre criança, acompanhante e equipe de saúde; (5) Possibilitar experimentação de sentimentos positivos; (6) Permitir uma postura mais pró-ativa e relaxada da criança; (7) Apontar habilidades desconhecidas da criança; (8) Promover a construção de novas habilidades; (9) Facilitar a construção de formas alternativas de comunicação; (10) Motivar acompanhante e equipe a continuar investindo na criança; (11) Promover a percepção de novas possibilidades de intervenção pela equipe; e (12) Mediar o processo de re-significação dos conceitos de paralisia cerebral, brincar e saúde.

Como estratégia de exposição dos resultados encontrados, optamos por inserir fragmentos de discursos de familiares, profissionais de saúde e crianças, obtidos na entrevista com os acompanhantes ou nas observações participantes. Essa inserção nos permitiu ilustrar o que foi observado no campo.

\section{Considerações acerca do contexto da brincadeira}

Durante a observação, notou-se que as crianças com PC permaneciam mais restritas ao leito. As razões para isso variavam muito: isolamento de contato em decorrência de colonização por alguma bactéria; dependência de oxigênio ou outro tipo de aparato tecnológico; administração de medicação ou dieta por bomba de infusão; ou ainda, por conta do elevado peso, tamanho e/ou comprometimento motor. 
Observamos que, muitas vezes, a equipe de saúde não autorizava a saída da criança do leito, mesmo quando essas justificativas orgânicas já haviam sido superadas. Frequentemente, a restrição ao leito era mantida por a equipe não acreditar em ganhos significativos do contato entre a criança com PC grave e outras com maiores possibilidades de interação.

Isso pode ser evidenciado em frases ditas durante a triagem por residentes de medicina, tais como: "Ah! Tirar do leito, pra quê? Ele não faz nada", ou ainda, "Se quiserem tirar, tira! Mas vai dar um trabalho... nem sei se ele vai aproveitar". De certa forma, essas restrições contribuíram significativamente para a manutenção do isolamento social dessas crianças dentro das enfermarias, além de evidenciar dificuldades claras da equipe de saúde em vislumbrar potencialidades, como já havia sugerido Diniz (1996).

Nas poucas oportunidades que tivemos para observar as crianças com PC no setting, percebemos que elas se tornaram personagens principais na dinâmica das atividades. Observamos que a presença delas nesse espaço evidenciou a dúvida de acompanhantes e equipe de saúde quanto às possibilidades de interação dessas crianças com outras. "Será que ele dá conta de ficar aqui com os outros? Vai brincar como?", disse uma enfermeira ao deslocar uma menina com PC para o setting.

Quando começaram a mostrar suas potencialidades, ficou patente na expressão e na fala das pessoas que as observaram, um misto de encanto e surpresa. "Nossa, ele está brincando mesmo, como pode?", nos disse a acompanhante de uma criança observando a interação entre sua filha sem PC e um menino com PC.

\section{Considerações acerca do papel do brincar na hospitalização}

Por conta das poucas possibilidades de deslocamento, a brincadeira dessas crianças acontecia com maior frequência no próprio leito. Nessas situações, eram levados alguns brinquedos até o box, a fim de que a criança pudesse escolher se queria, e do que queria brincar. Esses encontros evidenciaram que permitir à criança escolher o brinquedo e a brincadeira, viabilizou a expressão de sua individualidade, dando um lugar ativo a esse sujeito.

Um dos encontros com um menino de 5 anos, restrito ao leito, exemplifica essa discussão. Escolhemos carrinhos, boneca e um pianinho e fomos até o leito brincar com ele. Depois de algum tempo de experimentação com os brinquedos, ele optou pela boneca, indicando com as mãos que já podia guardar os demais. Pegou a boneca, deitou-a ao seu lado e a colocou para dormir, dando-lhe tapinhas nas costas. Quando escolheu a boneca e o tipo de brincadeira a ser desenvolvida, ele pode expressar suas preferências e apontar necessidades e possibilidades de intervenção. Assim, a forma como o brincar se desenvolveu relacionou-se com as demandas daquela criança naquele momento.

Certa tarde, atendemos outro menino de 5 anos. Ele estava restrito ao leito por conta de um acesso profundo na virilha. Tendo que usar luvas de gaze para impedir que tirasse o acesso, estava, portanto, com a movimentação ainda mais limitada. Além disso, estava em dieta zero há cerca de dois dias. Quando nos aproximamos dele, começou a chorar sinalizando que estava com fome, e que não queria brincar com nenhum dos brinquedos que tínhamos levado. Propusemos, então, brincar de comidinha de faz-de-conta. Ele aceitou. Preparávamos a comida, perguntávamos se ele gostava, se ele queria provar, e a levávamos até a sua boca. Depois de um tempo, ele sinalizou que já tinha comido muito e queria dormir. Com a brincadeira ele conseguiu expressar sua necessidade, elaborar de alguma forma aquela situação desprazerosa e relaxar.

Quando conseguimos brincar com ele, participamos desse processo, o que favoreceu a criação de vínculos e alianças. Nas entrevistas, os acompanhantes referiam-se a essa criação de vínculos em falas como a de uma das mães, "A brincadeira ajuda sim, 'cê' chega ele fica alegre. Ele tenta te 'chamá'. Ele já te conhece”.

No entanto, nem sempre esse brincar acontecia de forma espontânea. Nossas vivências mostraram que, em alguns casos, o acompanhante era o caminho mais adequado para se aproximar da criança. Observamos que acompanhante e criança tinham, comumente, uma relação de co-dependência, baseada em muita confiança e intimidade. Quando convidávamos o acompanhante a participar e mediar esse encontro, valorizávamos essa relação, o conhecimento dessas pessoas e o fazer próprio da criança. Isto nos possibilitou trazer para o hospital atividades prazerosas do dia a dia daquela família, que antecediam a própria história de adoecimento. Consequentemente, isso nos aproximava dessa família, facilitando o processo de construção de vínculo com a criança e seu acompanhante.

Um exemplo é o caso de um menino de 5 anos, internado acompanhado por seu bisavô. Quando fomos atendê-lo, foi o bisavô quem nos deu as dicas do que ele gostava e como se comunicava. Esse senhor funcionou como mediador do encontro com aquela criança. Mostrou a maior preocupação em relatar e traçar associações de acontecimentos e experiências do cotidiano de seu bisneto enquanto brincávamos. Aos poucos permitiu que nos aproximássemos dessa criança porque, segundo ele, "Você também sabe brincar com o C.".

Nas entrevistas, isso também foi evidenciado pela fala de diferentes acompanhantes: "Isso ajuda ele, porque ele gosta de cantar... Ele canta em casa", como disse a mãe de um dos meninos. Ou ainda, "Você chega, ela fica toda contente. Ela fica feliz, 'né'?!", constatou uma avó.

Observamos que o brincar possibilitou a criança com PC e seus acompanhantes experimentarem sentimentos positivos durante a hospitalização. Frequentemente, à medida que a brincadeira ia se desenvolvendo, notávamos sorrisos, relaxamento, gargalhadas e uma aproximação significativa desse acompanhante com a criança e conosco. Nas entrevistas, isso apareceu através de expressões como, "Ah! Imagina! Eu fico feliz!! É o meu prazer" ou ainda, "ele fica todo alegre ... ele acorda ... 'prá brincá' com 'aqueles carrinho'”. .

Observamos também, que o brincar auxiliou e estimulou o desenvolvimento global das crianças com PC. Por meio dele foi possível apontar habilidades desconhecidas e facilitar a construção de habilidades e formas alternativas de comunicação. 
Um exemplo é o de um menino que tinha acabado de realizar uma cirurgia quando começou a participar das atividades, Na cirurgia, foi feita uma traqueostomia, procedimento que retirou da criança a pouca capacidade que tinha de se comunicar oralmente. Com os atendimentos, começou a descobrir que seus braços e expressões faciais podiam dizer muito sobre suas necessidades e desejos, passando então a utilizá-los quando queria se comunicar. Nesses encontros, pudemos observar essa experimentação do corpo numa investida de interlocução, que foi se transformando em um processo complexo de comunicação.

Nas entrevistas, essa potencialidade do brincar foi evidenciada em falas que destacavam habilidades "descobertas" durante a brincadeira como a de uma mãe que disse: "(ele) aprendeu 'sentá' com a brincadeira aqui.". Ou de uma avó que, ao se referir às atividades realizadas pela neta, falou: “Quando veio pra cá (ela) não fazia nada ... 'tá'conseguindo falar assim agora, depois 'das brincadeira'”.

Certa vez, resolvemos levar para um dos meninos, além de alguns brinquedos, canetas hidrocor e papel. Quando chegamos, apresentamos as opções e ele escolheu pintar. Como tinha uma severa incoordenação motora no braço esquerdo, pediu para abrirmos as canetinhas e segurar o papel, enquanto ele desenhava com o braço direito. Lá pelo terceiro desenho, sua mãe, que estava almoçando, chegou. Quando viu as pinturas ficou muito emocionada, disse que não sabia que o filho podia pintar.

Resolvemos, então, fazer um mural no leito com os desenhos, e quando alguém da equipe de saúde entrava no box, ela logo dizia: "Olha o que D. sabe fazer! Ele fica olhando 'os irmão desenhá 'em casa ... Ele sabe desenhar”. E todos se surpreenderam, o elogiaram e contaram para outras pessoas. O brincar possibilitou a esse menino mostrar habilidades que nem nós, nem a mãe, nem as enfermeiras sabíamos que ele possuía.

Durante o estudo pudemos perceber que o brincar sistematizado fez com que tanto os acompanhantes, quanto a equipe, se motivassem a investir continuamente no processo de desenvolvimento das crianças. A imagem da criança brincando, muitas vezes, foi percebida pela equipe e família como um esforço de desenvolvimento: "A partir do momento em que a criança se esforça ... a mãe se sente mais motivada ...". Em geral, o recurso lúdico utilizado para tentar construir novas possibilidades de ação e expressão para essas crianças possibilitou a valorização das conquistas obtidas ao longo da hospitalização.

Tanto nas entrevistas, quanto em nossas observações, a possibilidade e a disponibilidade da criança com PC para o brincar no contexto da hospitalização foi vista como uma manifestação de saúde. Nas entrevistas, muitos acompanhantes relataram saber quando a criança estava melhor, ou pior, pela disposição que ela apresentava para brincar: "E sei quando ela 'tá'doente... ela só quer cama". Da mesma forma, muitas vezes fomos recebidos durante os atendimentos, com frases dos acompanhantes como "Hoje não 'tá' bem, não. Só 'qué durmi'”, ou ainda, "Já 'tá' melhor, 'tá' querendo 'brincá'e tudo".

Observamos que ao longo dos atendimentos o conceito que se tinha sobre paralisia cerebral, enquanto condição limitante e inviabilizadora de promoção do desenvolvimento e interação social, foi re-significado a partir do prisma das possibilidades. Assim, a criança com paralisia cerebral pode ser vista a partir de suas habilidades, de sua busca por autonomia e desejo de interação. O próprio conceito de brincar, enquanto atividade complexa e estruturada, pode ser renovado por uma perspectiva mais abrangente capaz de abarcar as singularidades de cada sujeito brincante. Isto é, a música, a dança e até o balbucio puderam ser integrados ao conceito de brincar, como vários entrevistados expressaram: "Eu não sabia que criança assim brincava", ou ainda, "Toda mãe gosta de ver seu filho bem, brincando com outras crianças ... É muito bom saber que ele pode 'brincá' com 'os outro'”.

No decorrer do estudo, notamos um aumento na frequência em que passamos a ser chamados pela equipe de referência das enfermarias para brincarmos com as crianças com PC grave. Nas reuniões com a equipe no pré-atendimento, alguns profissionais se aproximavam para compartilhar suas impressões sobre o desejo e os ganhos que o brincar parecia trazer para essas crianças. "Vocês vão brincar com L. hoje? Está tão tristinha ... Acho ela está precisando brincar", disse uma residente de medicina sobre uma criança com PC. É interessante destacar que alguns meses antes, a mesma residente tinha dito que essa menina não tinha possibilidades de interação. Dessa forma, foi possível perceber uma mudança na qualidade do olhar dos profissionais para essas crianças. Consequentemente, percebemos um ganho de visibilidade da criança com PC durante o seu processo de hospitalização.

\section{Discussão}

Os resultados desse estudo evidenciaram a dificuldade da equipe de saúde e de acompanhantes em se relacionar com a criança com paralisia cerebral grave por uma perspectiva diferente da mediada pela percepção da limitação. A forma como essas crianças foram apresentadas, sempre focando as inabilidades, refletiram a dificuldade desses profissionais e familiares em vislumbrar potencialidades e recursos, para além das sequelas e limitações. As consequências motoras advindas da lesão cerebral, entendidas como incapacidades, pareceram intensificar o que Diniz (2007) definiu como a estrutura opressora da deficiência. Mais difícil do que driblar os comprometimentos motores foi construir um espaço onde a criança com PC pudesse ser vista a partir de sua saúde, de suas possibilidades.

Acredita-se que pelo fato do brincar estar relacionado ao potencial de saúde da criança, como defendeu Winnicott (1971/1975), ele pode apontar potencialidades e habilidades. Os resultados desse estudo revelaram que o foco na saúde favoreceu a construção de um olhar integral para crianças com deficiência. A partir do brincar foi possível acessar a criatividade dessas crianças, facilitando o processo de desenvolvimento delas.

No entanto, a relação lúdica não se estabeleceu sem o que Maturana e Verden-Zöller (1928/2004) descreveram como a total aceitação corporal do outro. O brincar, para esses autores, é essencialmente espontâneo e despreocupado. A criança, quando brinca, não faz isso para aprender, construir, elaborar ou significar qualquer coisa. Embora isso tudo possa 
acontecer durante a brincadeira, não é isso que qualifica o brincar. $\mathrm{O}$ brincar tem um fim nele mesmo.

Nesse estudo pudemos observar que, de fato só, foi possível estabelecer uma relação lúdica com as crianças a partir da valorização de gestos, vocalizações e outros movimentos espontâneos e criativos. Foi possível perceber a expressão da subjetividade e a elaboração de situações potencialmente traumáticas, pelo fato de não ficarmos engessados, com uma postura pautada apenas no desempenho adequado das habilidades motoras. $\mathrm{O}$ brincar livre resgatou o ser e fazer próprios da criança a partir dessa relação de aceitação entre os brincantes. A comunicação estabelecida entre a criança e o pesquisador foi sempre uma comunicação no e pelo brincar. Assim, a linguagem mediadora do encontro com a criança com $\mathrm{PC}$ foi a linguagem lúdica. $\mathrm{O}$ brincar foi a linguagem que viabilizou e potencializou a comunicação com essas crianças, com a equipe e com os próprios acompanhantes.

As dificuldades de interação, advindas dos graves comprometimentos motores e da própria condição de $\mathrm{PC}$, de alguma forma foram superadas através do brincar. As restrições no movimento, locomoção, comunicação, aprendizado e desenvolvimento continuaram presentes (Geralis, 2007; Nunes, 2003), mas puderam ser re-significadas. Percebemos uma relação com o conceito de deficiência diferente da significação mais comum. A deficiência pode ser percebida como diferença e não como incapacidade (Glat \&Duque, 2003). Sendo a linguagem comum à infância, como propõe Santa-Roza (1999), o brincar possibilitou a aproximação dessas crianças com outras.

Nesse sentido, o brincar teve uma conotação de espaço de possibilidades. O brincar livre e sistematizado nas enfermarias, como propôs Saggese e Maciel (1996), apresentou-se um importante instrumento terapêutico para reduzir os danos causados pelo adoecimento e hospitalização da criança com PC. Ele favoreceu a construção de estratégias de intervenções focadas nas demandas apresentadas pelas crianças, como havia sugerido Takatori (2003). Além disso, a partir dos ganhos obtidos na brincadeira, pareceu ter ficado mais claro para os outros profissionais da enfermaria, e para a própria família, a possibilidade de promoção de uma melhora da qualidade de vida dessas crianças. As marcas da PC de alguma forma puderam abrir espaço para a expressão do sujeito, de sua condição de criança, facilitando o ganho de visibilidade dessas crianças durante o período de hospitalização.

\section{Considerações Finais}

A importância da qualidade das expectativas dirigidas às crianças com $\mathrm{PC}$ no que tange ao seu processo de desenvolvimento, evidenciada por Cunha (2003), aponta a necessidade da instrumentalização das pessoas de referência para mediação, facilitação e valorização no investimento da construção de habilidades motoras, cognitivas, afetivas, emocionais e sociais.

No entanto, para que a equipe de saúde possa promover uma atenção integral à criança com $\mathrm{PC}$, é preciso que leve em consideração os recursos e habilidades que essas crianças apresentam, integrando-os ao planejamento do tratamento, de forma a construir situações que favoreçam o desenvolvi- mento e percepção dessa criança durante a hospitalização. É necessário que ocorra uma mudança na qualidade do cuidado voltado à criança com PC, como sugeriu Diniz (1996). Em oposição a um olhar voltado para as inabilidades e deficiências, é preciso um olhar investido e integral.

Nesse contexto, o brincar livre durante a hospitalização se mostrou um importante recurso terapêutico. Brincar com as crianças com PC grave dentro das enfermarias foi uma experiência bastante enriquecedora. Com ele, foi possível reconhecer nessas crianças a busca por autonomia, subjetividade, saúde. Esse estudo evidenciou que essas crianças podem e devem ser vistas como agentes de seu desenvolvimento e evolução terapêutica, e não como organismos passivos bombardeados por estímulos, incapazes de tornarem-se mais independentes e autônomos. Mas, para isso, faz-se necessário o constante investimento e valorização das pequenas conquistas, que têm papel central no processo de desenvolvimento dessas crianças.

Acredita-se que pelo brincar se tratar de uma prática de domínio público é também uma prática inclusiva. Permite o diálogo entre as pessoas de referência da criança e os profissionais mais diversos. Através desse estudo, pode-se inferir que o brincar é a linguagem das possibilidades e das trocas, daí sua importância no contexto da hospitalização de crianças com PC.

\section{Referências}

Bardin, L. (1971). Análise de conteúdo. Lisboa: Edições 70.

Cunha, A.C.B. (2003). Os conceitos de zona de desenvolvimento proximal (ZDP) e aprendizagem mediatizada sob a perspectiva de análise da interação mãe-criança. Educare, Educere - Revista da Escola Superior de Educação de Castelo Branco, 15, 189-202.

Diniz, D. (1996). Dilemas éticos da vida humana: a trajetória hospitalar de crianças com paralisia cerebral grave. Cadernos de Saúde Pública, 12, 345-355.

Diniz, D (2007). O que é deficiência. São Paulo: Brasiliense

Geralis, E. (2007). Crianças com paralisia cerebral: guia para pais e educadores. Porto Alegre: Artmed.

Glat, R., \& Duque, M. A. (2003). Convivendo com filhos especiais: o olhar paterno. Rio de Janeiro: Viveiros de Castro.

Hage, S. (1996). Investigando a linguagem na ausência da oralidade. Em I. Marchesan, J., Zorzi \& I. Gomes (Orgs.), Tópicos em Fonoaudiologia (pp. 197-214). São Paulo: Lovise.

Maturana, H. \& Verden-Zöller, G. (2004). Amar e brincar: fundamentos esquecidos do humano. São Paulo: Palas Athena (Trabalho original publicado em 1928).

Minayo, M. C. S. (Org.) (1996). Pesquisa social: teoria, método e criatividade ( $6^{\mathrm{a}}$ ed.). Petrópolis: Editora Vozes.

Mitre, R. (2000). Brincando para viver: um estudo sobre a relação entre a criança gravemente adoecida e hospitalizada e o brincar. Dissertação de Mestrado, Instituto Fernandes Figueira/ FIOCRUZ, Rio de janeiro.

Nunes, L. (Org.) (2003). Favorecendo o desenvolvimento da comunicação em crianças e jovens com necessidades educacionais especiais. Rio de Janeiro: Dunya.

Nunes, L. R. P., Glat, R., Ferreira, J. R., \& Mendes, E. (1998). Pesquisa em educação especial na pós-graduação. Rio de Janeiro: Editora Sette Letras. 
Rosenthal, R. \& Jacobson, L. (1968). Pygmalion in the classroom. New York: Holt, Rinehart \& Winston.

Saggese, E. S. R \& Maciel, M. (1996). O brincar na enfermaria pediátrica: recreação ou instrumento terapêutico? Pediatria Moderna, 32, 290-292.

Santa Roza, E. (1997). Um desafio às regras do jogo. Em E. Santa Roza \& E. Reis (Orgs.), Da análise na infância ao infantil na análise (pp. 161-188). Rio de Janeiro: Contra Capa.

Santa Roza, E. (1999). Quando brincar é dizer: a experiência psicanalítica na infância ( $2^{\mathrm{a}}$ ed.). Rio de Janeiro: RelumeDumará.
Takatori, M. (2003). O brincar no cotidiano da criança com deficiência física: reflexões sobre a clínica da terapia ocupacional. São Paulo: Atheneu.

Winnicott, D. W. (1975). O brincar \& a realidade. Rio de Janeiro: Imago (Trabalho original publicado em 1971).

Recebido em 16.11.07 Primeira decisão editorial em 03.06.08 Versão final em 19.03.09 Aceito em 28.04.09 